\title{
PELAYANAN KESEHATAN PEDULI REMAJA MENURUT PERSPEKTIF REMAJA DI KOTA MAGELANG
}

\author{
Rohmayanti ${ }^{1}$, Irwan Taufiqur Rachman ${ }^{2}$, Wenny Artanty Nisman ${ }^{3}$
}

\begin{abstract}
Background:Teenagers have greater risk for health problems, especially sexuality and reproduction problems. Government has already developed Adolescent Friendly Health Services (AFHS). This program has already run in primary health care to overcome teenager's health problems. On the other hand, this program does not seem to accommodate some of teenager's expectation. Therefore, we need to conduct a research for knowing what kind of health services are suitable with teenager's perspective.

Objective: This study was design to explore type of AFHS which were suitable in adolescent's perspective.

Method: In this qualitative study, phenomenology was used for the approach. This study was conducted from September-October 2014 in primary health care region of Magelang. The participants for this study were 10-19 years old teenagers and they had already received adolescent friendly health services. The participants had been chosen using purposive sampling. The data was collected using focus group discussion, observation and indepth interview. Colaizzi's analysis had been used for data analysis manually.

Result and Discussion: Adolescent's perspective about AFHS consist of three theme. The first theme was adolescent perspective on existence of AFHS which was still various. The second theme was the perception of adolescents on the AFHS given in adolescents.The result was that not all six AFHS programs were given. The Third theme was adolescents hope for the result was AFHS health workers should be able to provide an explanation of the problems experienced by adolescents, be friendly, and the need to involve youth, teachers, parents and the community in AFHS services. Health Services that are conducted in teenagers, should be confidential,the service time was able to adjust school hours, use short massage, email for communication and information.

Conclusion: adolescent's have various expectations of the AFHS services in the future. Health services in accordance with the expectations of adolescents can be developed as a modified form of health care that can be implemented in AFHS primary health care.
\end{abstract}

Keywords: Adolescent Friendly Health Services (AFHS), Adolescent.

\begin{abstract}
ABSTRAK
Latar Belakang: Remaja sangat rentan terhadap berbagai ancaman risiko kesehatan terutama seksual dan reproduksi. Pemerintah telah mengadakan program Pelayanan Kesehatan Peduli Remaja (PKPR) yang dilaksanakan di puskesmas untuk mengatasi masalah kesehatan remaja. Program PKPR yang sudah berjalan, belum mengakomodir kepentingan remaja, sehingga perlu diketahui bagaimana pelayanan kesehatan peduli remaja yang sesuai dengan perspektif remaja.

Tujuan: Mengetahui pelayanan kesehatan peduli remaja (PKPR) menurut perspektif remaja.

Metode:Penelitian kualitatif dengan pendekatan fenomenologi. Subjek penelitian adalah remaja usia 10-19 tahun yang telah mendapatkan pelayanan kesehatan peduli remaja, dipilih secara purposive sampling. Pengumpulan data dengan cara FGD, observasi dan wawancara. Analisa data dilakukan secara manual, menggunakan tahapan analisa data menurut Colaizzi (1978). Penelitian dilakukan pada bulan September-Oktober 2014, di puskesmas wilayah Kota Magelang.
\end{abstract}

\footnotetext{
$\overline{{ }^{1} \text { Fakultas IImu Kesehatan, Universitas Muhammadiyah Magelang }}$

${ }^{2}$ Bagian Obstetri Ginekologi, Fakultas Kedokteran Universitas Gadjah Mada Yogyakarta

${ }^{3}$ Program Studi Magister Keperawatan, Universitas Gadjah Mada Yogyakarta
} 
Hasil dan Pembahasan: Perspektif remaja tentang PKPR terdiri atas tiga tema. Pertama, persepsi remaja tentang keberadaan PKPR masih sangat variatif. Kedua, persepsi remaja tentang program PKPR yang diberikan pada remaja, bahwa dari 6 program PKPR belum semua diberikan. Ketiga, harapan remaja terhadap PKPR ke depan bahwa petugas kesehatan harus mampu memberikan penjelasan tentang masalah yang dialami remaja, berlaku seperti sahabat, dan perlu melibatkan remaja, guru BP/UKS, orangtua serta masyarakat dalam pelayanan. Pelayanan dilakukan di tempat remaja berada, yang terjaga kerahasiaannya, waktu pelayanan menyesuaikan jam sekolah, perlu pemanfaatan sms, email untuk komunikasi dan informasi pada remaja.

Kesimpulan: Remaja memiliki berbagai harapan terhadap PKPR di masa depan. Pelayanan kesehatan yang sesuai dengan harapan remaja dapat dikembangkan sebagai bentuk modifikasi pelayanan kesehatan peduli remaja yang dapat diterapkan di puskesmas.

Kata Kunci: Pelayanan Kesehatan Peduli Remaja (PKPR), remaja.

\section{PENDAHULUAN}

Remaja berada di masa transisi, mereka memiliki keunikan dalam tahap pertumbuhan dan perkembangannya yang pesat secara fisik, psikologis maupun sosial. Pada masa ini, merupakan masa yang penuh dengan goncangan dan stress sehingga masalah yang dialami remaja, terlihat begitu kompleks. ${ }^{1}$ Remaja sangat berisiko terhadap masalah-masalah kesehatan reproduksi yaitu perilaku seksual pranikah, napza dan HIV/AIDS. ${ }^{2}$

Data dari bagian remaja dan lansia Dinas Kesehatan Kota Magelang ${ }^{3}$, masalah kesehatan remaja di Kota Magelang cenderung terjadi peningkatan dengan jumlah 20.255 remaja, sebanyak 92 remaja hamil, terdapat kasus infeksi menular seksual sebanyak 28 kasus, remaja yang merokok sejumlah 594 kasus, remaja pengguna obat terlarang dan alkohol sebanyak 10 kasus.

Sejak tahun 2003 Departemen Kesehatan sudah mencanangkan program pelayanan kesehatan peduli remaja (PKPR). Melalui PKPR di tingkat puskesmas, remaja dapat memperoleh pengetahuan mengenai kesehatan, tempat bersosialisasi, hingga mendapatkan pelayanan kesehatan yang memperhatikan kebutuhan remaja sehingga puskesmas berperanan penting dalam mewujudkan remaja sehat. ${ }^{4}$ Program PKPR telah dilaksanakan di Kota Magelang sejak tahun 2011 pada 5 puskesmas induk. ${ }^{3}$ Hasil studi pendahu- luan di dinas kesehatan mendapatkan hasil bahwa, program PKPR di Kota Magelang telah dijalankan, namun disisi lain kasus kehamilan, kasus penyakit penyakit menular seksual, ketergantungan obat terlarang dan alkohol terdapat peningkatan kasus.

Salah satu karakteristik PKPR adalah adanya partisipasi atau keterlibatan remaja. ${ }^{5}$ Remaja perlu dilibatkan secara aktif dalam perencanaan, pelaksanaan dan penilaian pelayanan. Ide dan tindak nyata mereka akan lebih mengena dalam perencanaan dan pelaksanaan pelayanan karena mereka mengerti kebutuhan mereka sendiri, mengerti "bahasa" mereka, serta mengerti bagaimana memotivasi sebaya mereka. ${ }^{6}$ Oleh karena itu, perlu program PKPR modifikasi yang diterima oleh remaja dengan melibatkan partisipasi remaja. ${ }^{7}$ Berdasarkan kondisi diatas, peneliti tertarik untuk mengeksplorasi pelayanan kesehatan peduli remaja menurut perspektif remaja di Kota Magelang.

\section{METODE}

Penelitian ini merupakan penelitian kualitatif dengan pendekatan fenomenologi. Partisipan dalam penelitian ini adalah remaja yang berusia 10-19 tahun yang telah mendapatkan pelayanan kesehatan peduli remaja pada puskesmas PKPR di wilayah Kota Magelang yang dipilih dengan menggunakan metode purposive sampling pada bulan September sampai November 2014. 
Instrumen yang digunakan adalah peneliti sendiri atau yang disebut dengan human instrument. ${ }^{9}$ Peneliti menggunakan alat bantu yaitu alat perekam, (voice recorder), buku catatan, pedoman FGD, pedoman observasi dan pedoman wawancara. Pengumpulan data dilakukan dengan metode Focus Group Discussion (FGD) pada remaja, observasi pada pelayanan kesehatan yang dilakukan di puskesmas dan wawancara mendalam dengan Kasi remaja lansia, pemegang program PKPR dan kepala puskesmas. Tahap awal adalah pengumpulan data, kemudian peneliti melakukan proses dokumentasi dengan membuat transkrip dalam bentuk verbatim berdasarkan hasil FGD, observasi, wawancara dan catatan lapangan (field note). Sebelum dianalisis peneliti membaca transkrip dan catatan lapangan beberapa kali agar dapat memahami data dengan baik dan dapat melakukan analisa data dengan tahapan analisis data menurut Colaizzi dalam 7 tahapan.

\section{HASIL DAN PEMBAHASAN}

Semua partisipan berjumlah 22 remaja dan semuanya telah mendapatkan pelayanan kesehatan peduli remaja minimal 1 kali. Peneliti juga melakukan triangulasi sumber dan triangulasi teknik dengan melakukan wawancara terhadap informan. Informan tersebut terdiri dari 3 (tiga) orang yaitu perawat pemegang program PKPR pada Puskesmas Magelang Selatan, Kepala Puskesmas Magelang Selatan dan Kasi Remaja Lansia Dinas Kesehatan Kota Magelang.

Perspektif remaja tentang PKPR terdiri atas tiga tema yaitu persepsi remaja tentang keberadaan PKPR, persepsi remaja tentang program PKPR berdasarkan jenis pelayanan yang diberikan, harapan tentang program PKPR yang akan datang.

1. Persepsi remaja tentang keberadaan PKPR

a. Kegiatan PKPR kurang dikenal oleh remaja Berdasarkan hasil FGD, diketahui bahwa remaja kurang mengenali tentang kegiatan PKPR yang dilakukan oleh
Puskesmas, seperti dalam pernyataan berikut:

"pelayanan remaja itu yang kayak gimana?(sambil mengerutkan dahi)" (Partisipan 1, FGD 1)

b. Pelayanan PKPR yang telah diberikan dirasakan kurang

Hasil penelitian ini menunjukkan bahwa remaja merasa pelayanan PKPR yang diberikan pada mereka hanya terbatas pada penyuluhan dan pelatihan saja.

"masih kurang jenis pelayanannya, hanya pelatihan kader kesehatan remaja yang diberikan" (Partisipan 4, FGD 1)

c. Remaja memiliki pemahaman tentang pengertian program PKPR

Meskipun remaja tidak mengenal keberadaan program PKPR, namun ada sebagian yang remaja mampu menyampaikan pemahaman mereka tentang PKPR sebagai berikut:

"pelayanan untuk...misalnya remaja yang bermasalah misalnya dalam kesehatannya atau psikologinya itu bisa luas ya.."(Partisipan 7, FGD 2)

2. Persepsi tentang program PKPR berdasarkan jenis pelayanan yang diberikan

a. Penyuluhan kesehatan telah didapatkan remaja 1 kali setahun pada masa orientasi sekolah dalam berbagai topik dan media yang digunakan.

"Saya pernah mendapatkan, apa itu, penyuluhan tentang kesehatan reproduksi disekolah..."(Partisipan 2, FGD 1)

b. Pelatihan kader kesehatan atau pelatihan pendidik sebaya diberikan pada remaja dengan topik dan media yang beragam namun sosialisasi yang dilakukan remaja masih terbatas.

"Kita datang ke sekolah tiap MOS saja, sama pendekatan ke sekolah.. kalau 
mereka minta kita masuk, tahun 2013...konselor itu kita undang di sini di Rabu minggu kedua, tiap sekolah 2 anak saja kalau ke sini" (I.1)

Sosialisasi hasil pelatihan sebaya dilakukan sesuai kemampuan remaja tiap sekolah, ada yang menyampaikan antar teman dan adapula yang menulis di majalah dinding.

"Menulis di mading sekolah, kita menghiasnya semenarik mungkin, enggak seadanya juga" (Partisipan 2, FGD 3).

c. Pemeriksaan klinis medis, didapatkan remaja di sekolah dalam bentuk pemeriksaan fisik pada mata, telinga, gigi, adapula pemeriksaan kesehatan di puskesmas. Seperti hasil observasi di puskesmas berikut ini

"Pemeriksaan klinis medis dilakukan pada remaja putri usia 14 tahun yang datang ke puskesmas sesuai keluhannya, pasien dengan diagnosa gastritis di anamnesa, di lakukan pemeriksaan fisik, diberikan konseling tentang menstruasi dan di beri obat (observasi).

d. Pelatihan keterampilan hidup sehat (PKHS) tidak diketahui oleh remaja, namun dari hasil observasi, remaja telah mendapatkannya, meskipun tidak mengetahui nama kegiatan tersebut.

"Saya mendapatkan materi pengertian merokok, kandungannya rokok, dampaknya, cara menghindar supaya tidak merokok" (Partisipan 5, FGD 1).

e. Rujukan didapatkan remaja setelah dilakukan pemeriksaan kesehatan secara rutin.

"Banyak...(yang mengalami gangguan) pada mata ada, telinga ada, di kasih rujukan" (Partisipan 8, FGD 2). f. Konseling belum didapatkan oleh remaja di sekolah, namun menurut petugas kesehatan serta hasil observasi, remaja yang datang ke puskesmas telah mendapatkan konseling.

"Memang tahun 2013 di unggulkan programnya, 2013 itu full kegiatan, dari konselor juga jalan..itu.. konseling jalan, semua jalan, nah untuk tahun 2014 ini walaupun sudah tidak jadi program unggulan tapi tetep programnya saya jalankan.. jadi setiap remaja yang datang kita konseling..."(pemegang program $P K P R)$.

3. Harapan tentang program PKPR yang akan datang

a. Petugas kesehatan

Sifat atau perilaku yang diharapkan oleh remaja ditunjukkan oleh petugas kesehatan yaitu mereka yang peduli, banyak senyum, ramah, mampu berkomunikasi, seperti sahabat, memahami karakter remaja sehingga dapat memberikan pelayanan kesehatan yang peduli remaja. Profesi yang dapat memberikan pelayanan adalah semua petugas yang merupakan ahli dan profesional dibidangnya.

"...mereka harusnya merangkul peduli.. dalam pelayanan harus senyum..ramah kita rangkul senyum, ramah jadi kalo kita yg dateng tuh enak.. yang sebelumnya punya masalah tuh bisa ngomong dan ada jalan keluarnya.." (Partisipan 2, 18th).

b. Remaja mengharapkan keterlibatan pihak lain

Pelayanan yang diberikan remaja akan efektif dengan melibatkan berbagai unsur yaitu remaja itu sendiri harus dilibatkan, keluarga dalam hal ini orang tua, pihak sekolah terutama guru BP dan UKS, serta masyarakat dilingkungan remaja tinggal. 
"...remaja perlu dilibatkan dalam hal konseling, penyuluhan..."(Partisipan 6, FGD 1)

c. Tempat dan waktu pelayanan

Remaja memerlukan tempat pelayanan yang nyaman yaitu ruangan yang tertutup, suasana nyaman, rahasia dapat terjaga, pelayanan bisa dilakukan di tempat remaja berada yaitu di sekolah pada jam yang sesuai dengan waktu remaja, bisa juga di luar sekolah dimana terdapat remaja pada tempat tersebut.

"Waktunya setelah jam sekolah..." Partisipan 2, FGD 1).

"Tertutup..jadi nyaman saat bisa masuk untuk konsultasi" (Partisipan 4, FGD 2)

d. Media pelayanan

Penyuluhan dan pelatihan serta pemeriksaan klinis medis yang langsung menjangkau remaja diharapkan dapat menggunakan berbagai media yang inovatif yaitu: media yang disesuaikan dengan kebutuhan remaja, penggunaan teknologi informasi melalui media sosial maupun pesan singkat yang mudah diakses remaja, pelayanan pada remaja difokuskan dengan membentuk tim khusus yang menangani remaja.

"...dari seminar bisa lebih sering.. bs pakai boneka, video medianya.. kalau hanya tulisan kurang ya..."( Partisipan 8, FGD 3)

"Dari tim penyuluh itu bisa membuat grup facebook yang tertutup" (Partisipan 7, FGD 2)

"Email, Facebook, sms" (Partisipan 6, FGD 1)

e. Jenis pelayanan

Bentuk pelayanan kesehatan yang diharapkan remaja berupa penyuluhan kesehatan remaja dengan berbagai topik, pelatihan kader kesehatan remaja yang dilakukan dengan media yang tepat, pemeriksaan kesehatan dengan petugas yang komunikatif, adanya konseling masalah remaja.

"kayak seminar, konseling itu, gimana caranya kita menyampaikan ke anak remaja..."( Partisipan 2, FGD 3).

“...pemeriksaan, penyuluhan, konseling" (Partisipan 4, FGD 2)

"...kasih video, berinteraksi dengan peserta" (Partisipan 6, FGD 3).

"mungkin bagaimana cara mencari jati diri yang benar..."( Partisipan 7, FGD 2)

Program PKPR yang diberikan pada remaja belum semua diberikan sesuai jenis kegiatan PKPR, jenis pelayanan yang perlu ditambahkan adalah konseling, diharapkan membentuk tim khusus pelayanan remaja, pelayanan dilakukan di sekolah dan luar sekolah, tempat pelayanan yang nyaman dan tertutup, dilakukan di luar jam sekolah atau jam istirahat, perlu pemanfaatan media sosial untuk menunjang komunikasi dan informasi pada remaja. Petugas kesehatan harus mampu memberikan penjelasan tentang masalah yang dialami remaja, berlaku seperti sahabat, ramah dan perlu melibatkan remaja, guru BP/UKS, orangtua serta masyarakat dalam pelaksanaan program PKPR.

Responden dalam penelitian ini menyatakan pentingnya pelayanan kesehatan peduli remaja karena remaja sedang mencari jati diri. Menurut $\mathrm{WHO}^{8}$ remaja memerlukan pelayanan kesehatan remaja untuk mengurangi kematian dan penyakit pada remaja, mengurangi resiko penyakit di kemudian hari, merupakan inventasi dalam kesehatan yang akan datang, menjamin hak asasi manusia dan melindungi masa depan manusia.

Remaja memahami program PKPR sebagai pelayanan yang peduli dengan keadaan remaja, yang difokuskan pada masalah remaja dalam hal 
kesehatannya atau psikologinya atau secara luas, dari ahlinya kepada remaja. Hal ini sesuai dengan pengertian PKPR menurut Depkes $\mathrm{RI}^{6}$ yaitu merupakan pelayanan kesehatan yang ditujukan dan dapat dijangkau oleh remaja, menyenangkan dan menerima remaja dengan tangan terbuka, menghargai remaja, menjaga kerahasiaan, peka akan kebutuhan terkait dengan dengan kesehatannya secara efektif dan efisien dalam memenuhi kebutuhan tersebut. Pemahaman remaja ini menunjukkan bahwa persepsi mereka dibentuk oleh sisi kognitif serta pengalaman selama mendapatkan pelayanan kesehatan remaja. ${ }^{6,10}$

Faktor yang berkontribusi dalam membentuk ketidakpuasan atau ketidakpercayaan pasien remaja antara lain petugas kesehatan kurang menjaga hubungan baik dengan pasien, remaja takut jika hasil pemeriksaan diketahui secara umum, kurangnya komunikasi, dan adanya persepsi yang kurang baik terhadap dokter. Ketakutan akan pengalaman yang akan mereka hadapi seperti pemeriksaan yang tidak perlu, pemeriksaan fisik pada remaja atau pengobatan yang akan mereka jalani menjadi faktor yang paling dominan dalam. ${ }^{11}$

Pemahaman remaja terhadap program PKPR menyebabkan remaja memiliki persepsi dan penilaian terhadap perlu atau tidaknya pelayanan kesehatan remaja. Penelitian Afrima ${ }^{12}$ menyebutkan bahwa siswa yang menerima adanya PIK-KRR (Pusat Informasi dan Konsultasi Kesehatan Reproduksi Remaja) dan memiliki sikap yang positif terhadap kesehatan reproduksi akan meningkatkan pemanfaatan PIK-KRR sebanyak 1,4 kali dibandingkan siswa yang tidak menerima PIK-KRR.

Berdasarkan pengalaman partisipan, remaja belum mendapatkan semua program PKPR, yang didapatkan yaitu penyuluhan kesehatan, pelatihan konselor/kader remaja, dan pemeriksaan kesehatan. Sedangkan, menurut keterangan dari pemegang program PKPR, semua pogram sudah dilakukan, selain kegiatan diatas ditambah pelatihan keterampilan hidup sehat, konseling, dan rujukan. Menurut Depkes $\mathrm{RI}^{6}$ jenis kegiatan PKPR meliputi penyuluhan, pelayanan klinis medis termasuk pemeriksaan penunjang, konseling, pendidikan keterampilan hidup sehat (PKHS), pelatihan pendidik sebaya (pelatihan menjadi kader kesehatan remaja) dan konselor sebaya (pendidik sebaya yang diberi tambahan pelatihan interpersonal relationship dan konseling), serta pelayanan rujukan. ${ }^{6}$

Sosialisasi ilmu yang didapat remaja setelah mengikuti penyuluhan maupun pelatihan belum dapat dilakukan oleh sebagian besar partisipan. Kewajiban untuk menyampaikan ilmu atau pengetahuan yang didapat seharusnya dilakukan terutama oleh mereka yang mendapatkan pelatihan yang disebut konselor remaja atau kader kesehatan remaja. Pendidik atau konselor remaja merupakan mentor atau advokat remaja. Peningkatan pelayanan kesehatan remaja dapat dilakukan dengan mengoptimalkan peran konselor remaja. ${ }^{6,13}$

Keterbatasan yang ada pada petugas kesehatan, menurut remaja yang menjadi partisipan dalam penelitian ini adalah dalam hal kurang menguasai materi dari narasumber pada saat penyuluhan/ pelatihan kesehatan, sikap petugas kesehatan pada pemeriksaan kesehatan kurang dan keterbatasan waktu pelayanan. Berdasarkan hasil wawancara dengan pemegang program PKPR, petugas sudah mendapatkan pelatihan konselor remaja, dan petugas lainnya mendapatkan refreshing materi, namun dalam pelaksanaan kegiatan, mereka memiliki hambatan dalam hal sumber daya manusia yang terbatas jumlahnya, tugas lain diluar kegiatan PKPR yang menyita waktu mereka. Sesuai dengan penelitian Alizadeh, et al..$^{14}$ terdapat hambatan dalam melaksanakan pelayanan kesehatan remaja : adanya tugas yang banyak dan tidak kompatibel dengan pelatihan dasar mereka, kurang optimalnya supervisi dan managemen, terlalu sedikit waktu untuk pasien, kurangnya privasi dan ketepatan bahan untuk edukasi dan konseling, kurangnya kesempatan untuk pendidikan lanjut. ${ }^{14}$ 
Berdasarkan analisa data hasil FGD, penelitian ini menghasilkan satu tema yaitu pelayanan kesehatan yang sesuai dengan kebutuhan remaja yang meliputi: Jenis pelayanan kesehatan yang diharapkan remaja berupa penyuluhan kesehatan remaja dengan berbagai topik, pelatihan kader kesehatan remaja yang dilakukan dengan media yang tepat, pemeriksaan kesehatan dengan petugas yang komunikatif, dan yang belum dilaksanakan menurut remaja yaitu adanya konseling masalah remaja. Pendidikan kesehatan reproduksi dapat meningkatkan pengetahuan remaja terhadap pentingnya kesehatan reproduksi, sehingga remaja dapat bertanggung jawab atas keputusannya mengenai perilaku seksualnya. Pendidikan seksual dapat meningkatkan pengetahuan, keterampilan, nilai-nilai untuk membuat keputusan yang bertanggung jawab terhadap perilaku seksual remaja. ${ }^{15}$

Hasil penelitian ini menunjukkan bahwa pelatihan konselor remaja sudah diberikan oleh puskesmas. Oleh karena itu, ke depan diperlukan upaya untuk meningkatkan peran konselor agar dapat melakukan konseling pada remaja sebayanya. Remaja seharusnya menjadi pelopor program kesehatan remaja (dari oleh dan untuk remaja) sehingga remaja perlu menyampaikan kepada stakeholder (decision maker dan provider) bahwa ada permasalahan remaja baik yang dialami secara pribadi maupun pengalaman orang lain, kebutuhan akan program kesehatan remaja, ketersediaan remaja untuk terlibat aktif dalam pelaksanaan program PKPR. ${ }^{16}$

Sifat atau perilaku yang diharapkan oleh remaja ditunjukkan oleh petugas kesehatan yaitu mereka yang peduli, banyak senyum, ramah, mampu berkomunikasi, seperti sahabat, memahami karakter remaja sehingga dapat memberikan pelayanan kesehatan yang peduli remaja. Berdasarkan pedoman $\mathrm{WHO}^{8}$ penyedia layanan kesehatan ramah remaja adalah teknisi yang berkompetensi dalam bidang khusus masalah remaja. Menurut Alizadeh, et al. ${ }^{14}$ untuk meningkatkan produktivitas pelayanan remaja maka yang pertama diperlukan intervensi mencakup kebutuhan pendidikan pra pelayanan, petugas kesehatan melakukan pelatihan sebelum melakukan pelayanan pada remaja, kemudian melakukan pengawasan dan memiliki manajemen yang mendukung, disediakan materi pendidikan yang cukup, menyederhanakan birokrasi atau administrasi, menunjuk staf atau tim khusus remaja. ${ }^{8,14}$

Pelayanan yang baik dibutuhkan remaja agar mereka mau memanfaatkan sarana pelayanan yang ada. Penyuluhan dan pelatihan serta pemeriksaan klinis medis yang langsung menjangkau remaja diharapkan dapat memanfaatkan berbagai media teknologi informasi/multimedia dan sosial media serta sarana pelayanan yang nyaman.. Materi KIE (Komunikasi Informasi Edukasi) perlu disediakan, perlu leaflet yang boleh dibawa pulang tentang berbagai tips atau informasi kesehatan remaja, hal ini berguna untuk memberikan pengetahuan melalui bahan bacaan dan promosi adanya PKPR kepada sebaya yang ikut membacanya. ${ }^{6}$ Penelitian oleh Purwidianti ${ }^{17}$ mengenai perangkat pembelajaran pendidikan kesehatan reproduksi berupa penyusunan modul, multimedia presentasi dan $C D$ interaktif yang dikembangkan memberikan hasil ketuntasan belajar PKR (> 86) dan peningkatan persepsi siswa terhadap permasalahan reproduksi yang signifikan. ${ }^{17}$

Pelayanan yang efektif menurut remaja dapat dilakukan dengan pemanfaatan informasi teknologi (IT) melalui penggunaan media sosial berupa facebook, twitter atau menggunakan pesan singkat melalui BBM, sms agar petugas kesehatan maupun remaja tidak terhalang oleh waktu yang terbatas. Blog, jejaring sosial dan wiki merupakan bentuk media sosial yang paling umum digunakan oleh masyarakat di seluruh dunia. Pemanfaatan sosial media sebagai media pembelajaran disebabkan karena media ini lebih mendekatkan pada situasi riil, sehingga siswa lebih tertarik untuk berpartisipasi dalam proses pembelajaran. ${ }^{18}$ 
Menurut Depkes $\mathrm{RI}^{6}$ dalam karakteristik PKPR mencakup berbagai hal antara lain petugas khusus yang peduli remaja, petugas pendukung yang peduli remaja, adanya sarana prasarana yang mendukung. Pendayagunaan petugas puskesmas dalam pelayanan kepada remaja menjadi sangat penting agar remaja mau memanfaatkan PKPR. ${ }^{5}$

Remaja memerlukan tempat pelayanan yang nyaman yaitu ruangan yang tertutup, suasana nyaman, rahasia dapat terjaga, pelayanan bisa dilakukan di tempat remaja berada yaitu di sekolah pada jam yang sesuai dengan waktu remaja, bisa juga di luar sekolah dimana terdapat remaja pada tempat tersebut. Karakteristik pelayanan kesehatan reproduksi yang menjadi idaman bagi remaja adalah terdiri dari beberapa dimensi yaitu privasi, mendapat kepuasan dengan pelayanan yang bersifat bersahabat dan kenyamanan. Waktu pelayanan yang sama dengan jam sekolah akan menghambat akses pelayanan, jam pelayanan yang menyesuaikan waktu luang remaja menjadikan konseling dan pelayanan lain dapat dilaksanakan santai tidak terburu-buru dan pemecahan masalah dapat diberikan. ${ }^{6,19}$

Pelayanan yang diberikan remaja akan efektif dengan melibatkan berbagai unsur yaitu remaja itu sendiri harus dilibatkan, keluarga dalam hal ini orang tua, pihak sekolah terutama guru BP dan UKS, serta masyarakat dilingkungan remaja tinggal. Menurut Setiasih ${ }^{17}$ untuk menyediakan lingkungan yang mendukung, kebijakan seharusnya dapat meningkatkan mutu ketersediaan pelayanan kesehatan remaja, menguatkan kerjasama antar institusi dan LSM, menguatkan partisipasi keluarga dan masyarakat, memastikan adanya partisipasi aktif remaja untuk pelaksanaan program ini. ${ }^{19}$

\section{KESIMPULAN DAN SARAN}

Penelitian ini menghasilkan suatu bentuk pelayanan yaitu pelayanan kesehatan yang sesuai dengan kebutuhan remaja. Jenis pelayanan kesehatan remaja yang perlu ditambahkan yaitu pelayanan konseling masalah remaja. Sifat atau perilaku petugas kesehatan yang diharapkan oleh remaja yaitu mereka yang mampu berkomunikasi, berlaku seperti sahabat, dan memahami karakter remaja.

Pelayanan kesehatan pada remaja difokuskan dengan membentuk tim khusus yang menangani remaja. Sarana kesehatan yang dibutuhkan remaja yaitu ruangan yang nyaman, tertutup dan pelayanan bisa dilakukan di puskesmas, di sekolah maupun diluar sekolah pada jam yang sesuai dengan waktu remaja yaitu diluar jam sekolah atau jam istrahat. Perlu pemanfaatan multimedia dalam penyuluhan dan pelatihan serta perlu penggunaan sosial media seperti email, pesan singkat sebagai sarana komunikasi dan informasi. Keterlibatan pihak lain dalam pelaksanaan PKPR yaitu remaja, orang tua, guru BP/UKS, serta masyarakat dilingkungan remaja tinggal.

Hasil penelitian ini berupa bentuk pelayanan kesehatan yang sesuai dengan kebutuhan remaja dapat diterapkan pada keilmuan keperawatan khususnya komunitas maternitas di tingkat pra maupun pasca konsepsi untuk meningkatkan kualitas hidup remaja. Mengadakan pelatihan khusus petugas kesehatan sebagai trainer konselor remaja. Melakukan pelayanan konseling remaja diluar dan di puskesmas, melakukan pelayanan dengan metode, materi, media, ruangan, waktu dan tempat pelayanan yang sesuai dengan kebutuhan remaja. Memanfaatkan sosial media berupa grup facebook dengan keanggotaan tertutup serta menerima layanan pesan singkat, waktu tidak dibatasi. Meningkatkan keterlibatan sekolah dengan menambah MOU di setiap sekolah, meningkatkan peran aktif kader kesehatan remaja, keterlibatan orangtua melalui sekolah dengan peran aktif dari guru BP, serta meningkatkan keterlibatan masyarakat melalui organisasi masyarakat seperti karangtaruna. 


\section{DAFTAR PUSTAKA}

1. Depkes. Remaja dan Permasalahannya. Jakarta: Depkes RI. 2011.

2. Utomo, I.D., P.M.A. Reimondos., T. Hull., dan A. Utomo. Reproductive Health Services for Single Young Adult (The 2010 Greater Jakarta Transition to Adulthood Study). Policy Brief No. 5. Australian Demographic and Social Research Institute, Australian National University. 2010.

3. Profil Kesehatan Kota Magelang, 2012. Dinas Kesehatan Kota Magelang. Magelang.

4. Arsani, N.L.K.A., N.N.M. Agustini., I.K.I. Purnomo. Peranan program PKPR (Pelayanan Kesehatan Peduli Remaja) Terhadap Kesehatan Reproduksi Remaja di Kecamatan Buleleng. Jurnal IImu Sosial dan Humaniora. 2013.2 (1): 2303-2898.

5. World Health Organization. Making Health Services Adolescent Friendly. Developing National Quality Standards For Adolescent Friendly Health Services. Switzerland. Department of Maternal, Newborn, Child and Adolescent Health. Available from: http:/ /who.int/childadolescent-health. 2012.

6. Depkes, Direktorat Jenderal Bina Kesehatan Masyarakat. Pedoman Pelayanan Kesehatan Peduli Remaja di Puskesmas. Jakarta. Depkes RI. 2005.

7. Sarah, R.C.L., Implementasi Program pelayanan Kesehatan Peduli Remaja (PKPR) di Puskesmas (Studi Kasus di Kabupaten Sumbawa Barat). Tesis. Universitas Gadjah Mada. Yogyakarta. 2012.

8. World Health Organization. Making Health Services Adolescent Friendly. Developing National Quality Standards For Adolescent Friendly Health Services. Available from: http://who.int/childadolescenthealth. 2002.

9. Bungin, B. Analisis Data Penelitian Kualitatif. Edisi Pertama. Cetakan Ke-delapan. Raja Grafindo Persada. Jakarta. 2012.

10. Walgito, B.Pengantar Psikologi Umum. 4 ed, Yogyakarta: Andi offset . 2004.
11. Miller., M.K., Dowd. Denise., L. Jennifer., J. Sara. Accessing Healthcare: Experiences of Urban Youth. Poster Symposia. 2014.54: S17-S33.

12. Afrima, Arie. Akseptabilitas dan Pemanfaatan Pusat informasi dan Konsultasi Kesehatan Remaja (PIKKRR) Pada Siswa SMU di Kota Bima NTB. Tesis. Universitas Gadjah Mada. Yogyakarta. 2011

13. Hausman-Muela, S., Ribera, J.M. \& Myaongo.IHealth Seeking Behavior And The Health System Reproductive. DCPP Working Papav No 14.geneva.UNDP//Work Bank/WHO. . 2003.

14. Alizadeth C,S.M., R. Wahistorm., R. Vahidi., A. Nikniaz., L. Marions., dan A. Johansson.. Barriers To High-Quality Primary Reproductive Health Services In An Urban Area Of Iran: Views Of Public Health Providers. 2009. Midwifery 25:721-730.

15. Fadhlina, D. 2012. Pelaksanaan PKPR 2012. http:// pkpr.datainformasi.net/berita-101-pelaksanaanpelayanan-kesehatan-peduli-remaja-pkpr.html. 18 Maret 2014 (14.30).

16. Muthmainnah, Analisis Stakeholder Remaja Terhadap Implementasi Program Pelayanan Kesehatan Peduli Remaja (PKPR) Di Kota Semarang. Jurnal Promkes. 2013. 1 (2): 170-183.

17. Purwidianti, N; F. Mutimmatul, A.C.A.Nur. Peningkatan Kesehatan Reproduksi Berbasis Multimedia Bagi Siswa SMA Untuk Mengatasi Problem Pergaulan Bebas Remaja. Universitas Negeri Surabaya. 2009.

18. Gabarron, E, A. Serrano, R. Wynn \& M. Armayones. Avatars using computer/smartphone mediated communication and social networking in prevention of sexually transmitted diseases among NorthNorwegian youngsters. BMC Med Inform Decis Mak. 2012. (12: 120).

19. Setiasih, E. The Adolescent in Indonesia: Kesehatan Remaja di Tanah Air. Jakarta.Sagung Seto. 2007. 